\title{
Quantitative analysis of localized corrosion in tensile armor wire of flexible riser submitted to sweet stress corrosion cracking testing with crevice
}

\author{
Matheus Porto Trindade $1 *$ (1) \\ Ihana Gabriela Conceição de Jesus ${ }^{1}$ \\ Matheus Mariano da Silva Reis ${ }^{1}$ \\ Brenno Lima Nascimento ${ }^{1}$ \\ Fabricio Pinheiro dos Santos ${ }^{2}$ \\ Sandro Griza
}

\begin{abstract}
Failure of flexible risers can occur, among several factors, due to their cold drawn carbon steel tensile armor wires collapse. These wires are susceptible to corrosion by seawater which increases propensity to a synergistic sweet stress corrosion mechanism, when they are associated with $\mathrm{CO}_{2}$-saturation, high tension, pressure, temperature, and crevices occurrence. In the present study, the influence of crevice in the annular region of flexible risers on the severity of pitting corrosion was quantified. Two different cold drawn carbon steel wires were compared. Corrosion tests by immersion were carried out on wires subjected to three-point bending in synthetic seawater environment at $0.1 \mathrm{MPa}, 25^{\circ} \mathrm{C}$ and $2 \mathrm{MPa}$, $60^{\circ} \mathrm{C}$. The crevice occurrence and the internal energy were significant intensifying factors for pitting corrosion, which was demonstrated by the higher frequency and depth of the pittings and by the arrangement of corrosion deposits in crevice assembly samples. The carbon content of the wire did not significantly influence corrosion.
\end{abstract}

Keywords: Risers; Crevice corrosion; Stress corrosion; Tensile armor wires.

\section{Introduction}

Flexible risers are widely applied on floating offshore platforms worldwide and they are considered a standard fluid conduction system in several offshore units in Brazil [1,2]. The oil production in the pre-salt fields in Brazil has been increasing [3], whose reserves are considered as heavy oil (higher relative densities) and sweet oil (basically composed of hydrocarbons and $\left.\mathrm{CO}_{2}\right)[3,4]$. Kermani and Harrop [5] denotes that corrosion in the oil industry can be related to the $\mathrm{CO}_{2}$ saturated environment, which leads to the formation of $\mathrm{H}_{2} \mathrm{CO}_{3}$ [4]. The use of carbon steel in riser's metallic armor due to their lower overall cost, increases the corrosion susceptibility [6].

The space between polymeric protective layers in which the carbon steel tensile armor wires are located is called annular and has a basically structural function. Failures related to the annular are particularly sensitive, since there is a much greater propensity for collapse due to accelerated corrosion compared to the polymeric and stainless steel alloy components on the riser's outside and inside layers, respectively [7]. The permeability of annulus' polymeric layers exposes steel wires to corrosion [8] and its severity is important $[9,10]$. Stress corrosion cracks (SCC) associated with crevice corrosion can occur in the wires and they cause accelerated degradation processes related to carbon oxides and carbides [11,12]. The combination of the mechanisms provides pitting in the carbon steel.

In this study, crevice corrosion between flexible riser's polymeric layers and carbon steel armor wires was evaluated, relating it to pitting corrosion intensity. Flexible riser's annulus operating conditions were emulated, considering $\mathrm{CO}_{2}$-saturated deep-water system, followed by quantitative and qualitative evaluation of pittings formed in armor wires surfaces.

\section{Materials and methods}

\subsection{Wire characterization}

The two new straight wires (cross section $14 \times 6) \mathrm{mm}$, with dissimilar chemical contents were named as 1 and 2 . The preparation of the wires was made by simple cuts to adjust the length and cleaning with water and surfactant. Chemical analysis was performed on the two wire's steel

${ }^{1}$ Pós-graduação em Ciencia e Engenharia de Materiais, Universidade Federal de Sergipe - UFS, São Cristóvão, SE, Brasil.

${ }^{2}$ Centro de Pesquisas Leopoldo Américo Miguez de Mello - CENPES-PETROBRAS, Rio de Janeiro, RJ, Brasil.

*Corresponding author: matheusportot@gmail.com 
by optical emission spectrometer (Foundry Master XPert Oxford). Two samples of each wire were analyzed to give the chemical content. Samples were polished for optical micrographic analysis (Zeiss Axio Lab.A1) and etched by Nital 2\% solution. Vickers microhardness tests (Future Tech FM-800) were performed on the samples, applying $1000 \mathrm{gf}$ load. Roughness analysis (Ra scale Mitutoyo SJ-410) was also performed on the wire samples at a speed of $0.5 \mathrm{~mm} / \mathrm{s}$ of the stylus over the surface, measuring a length of $4.8 \mathrm{~mm}$.

\subsection{Stress corrosion cracking tests at 20 bar $\mathrm{CO}_{2}$ pressure and $60^{\circ} \mathrm{C}$}

The $150 \mathrm{~mm}$ long specimens were subjected to threepoint bending (TPB) in $130 \mathrm{~mm}$ spam. Although in TPB the localized corrosion might not match with the most stressed region, therefore reducing the chance of reproducing cracks, the choice for TPB was made to have a very local stress plateau matching the crevice promoted by polyethylene plates (HDPE). The deflection corresponding to the average yield strength of the wires was obtained, according to ASTM E290-14 for static tension systems, as specified in ASTM G39 (Figure 1).

TPB test yield strength and deflection of the wire 1 and wire 2 were, respectively, $1364 \mathrm{MPa}$ and $4.7 \pm 0.2 \mathrm{~mm}$; $957 \mathrm{MPa}$ and $3.5 \pm 0.2 \mathrm{~mm}$. The deflection was assessed by coordinate measuring machine (Mitutoyo Crysta-Apex S 574). To ensure the same deflection in both wires, the maximum deflection line in relation to the wire face at supporting pins was measured on the elastic line. Specimens of both wires were tested with and without mounting of polyethylene plates and polytetrafluoroethylene (PTFE) tapes wrapped around the ends of the specimens, emulating the occurrence of crevice. Four analysis groups were evaluated as follows: wire 1 without layer and tapes (W1), wire 1 with HDPE layer and PTFE tape (PW1), wire 2 without layer and tapes (W2) and wire 2 with HDPE layer and PTFE tape (PW2).
Three specimens of each group were placed in the autoclave (Figure 1). The specimens were submerged in synthetic seawater (ASTM D1141) heated at $60{ }^{\circ} \mathrm{C}\left( \pm 2{ }^{\circ} \mathrm{C}\right)$. This temperature corresponds to the riser's operational typical temperature range [13] and to the noticeable increase in corrosion effects observed in similar studies [14,15]. At the first week the test was performed under atmospheric pressure. A purge was performed to replace atmospheric air with $\mathrm{CO}_{2}$-saturated atmosphere. Then, $2 \mathrm{MPa}(20 \mathrm{bar}$ ) of $\mathrm{CO}_{2}\left(99,999 \%\right.$ purity; $<2 \mathrm{ppm} \mathrm{O}_{2}$ content) working pressure was applied. Water volume and exposed metallic area ratio (V/A) was fixed at $1 \mathrm{ml} / \mathrm{cm}^{2}$. The test was carried out for three months.

Pitting analysis was performed in longitudinal metallographic sections of the specimens, using optical microscopy (Zeiss Axio Scope.A1 + Canon EOS 1000D). The tensioned face of the wires was analyzed. The length of analysis was $54 \mathrm{~mm}$ ( $27 \mathrm{~mm}$ for each side from the loading pin). The frequency and depth of pitting were determined by Fiji-Image J software, from micrograph binarization and gray pixel $\mathrm{x}$ distance plot, which were later converted into depth $\times$ distance plot. The two largest valleys and peaks of a given investigated surface were considered as limits for analysis. An illustration of the applied method is shown in Figure 2.

Significant differences in the pitting depth were analyzed by analysis of variance (ANOVA), at the significance level of $0.05(5 \%)$, whose lower values (p-values) reject the null hypothesis that there is no significant difference between groups.

Raman spectroscopy tests (Brüker Optics Senterra R200-785) were performed on samples to give the nature of corrosion deposits in the pitting.

\section{Results and discussion}

Chemical analysis results are shown in Table 1. Wires 1 and 2 exhibited a high and medium commercial
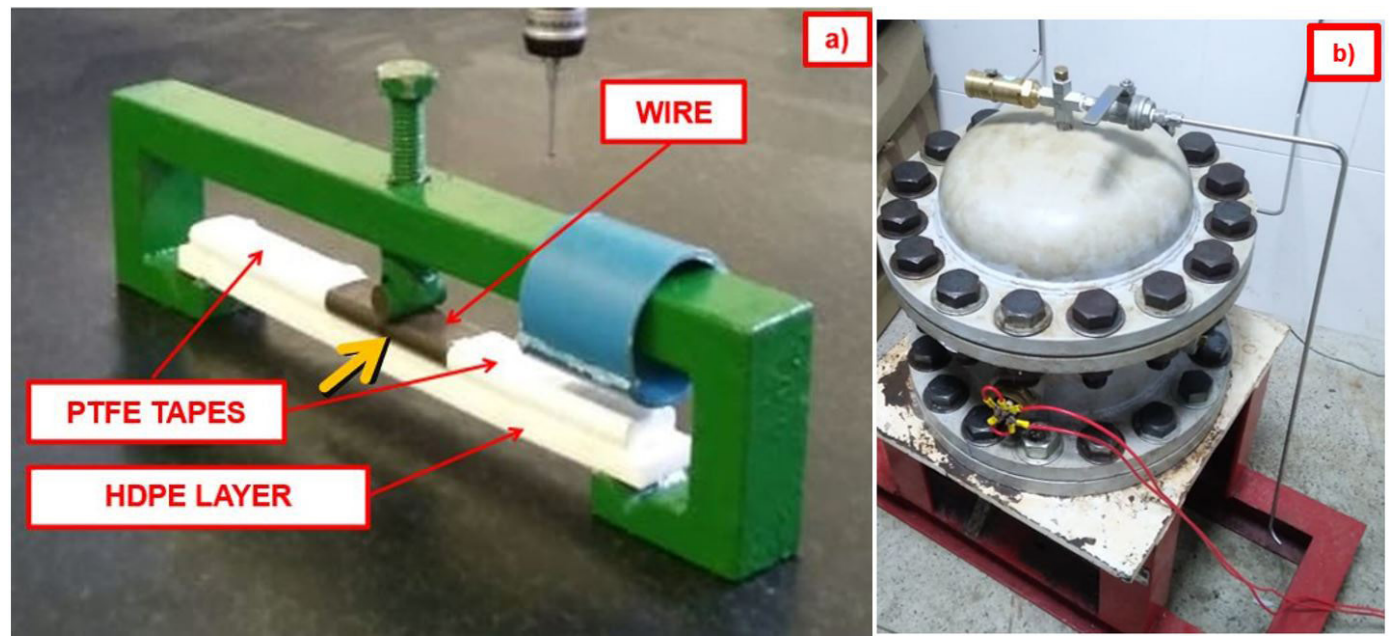

Figure 1. (a) Three-point bending individual support assembled with wire and HDPE layer, emulating the polymeric layer and a gap which encourages crevice. Golden arrow indicates where crevice occurs due to the gap imposed by PTFE tapes and (b) stress corrosion test autoclave in operation. 
carbon steel chemical composition respectively, both as manganese alloy [16].

The microstructure of the wires, shown in Figure 3, is composed by highly cold-worked ferrite and perlite. Metallography showed great similarity to $70 \%$ cold drawn carbon steel microstructure [17] Tensile armor wires microstructures studied by Tagliari et al. [18] also presented a longitudinal section with similar features.

Vickers microhardness was significantly different between Wire $1(320 \pm 3 \mathrm{HV})$ and Wire $2(367 \pm 3 \mathrm{HV})$. Surface roughness was significantly different between

Table 1. Tensile armor wires steel chemical content (wt $\%)$

\begin{tabular}{ccccccc}
\hline Sample & C & Si & Mn & P & S & Al \\
\hline Wire 1 & 0.72 & 0.20 & 0.72 & 0.016 & 0.012 & 0.04 \\
Wire 2 & 0.36 & 0.21 & 0.65 & 0.014 & 0.011 & 0.04 \\
\hline
\end{tabular}
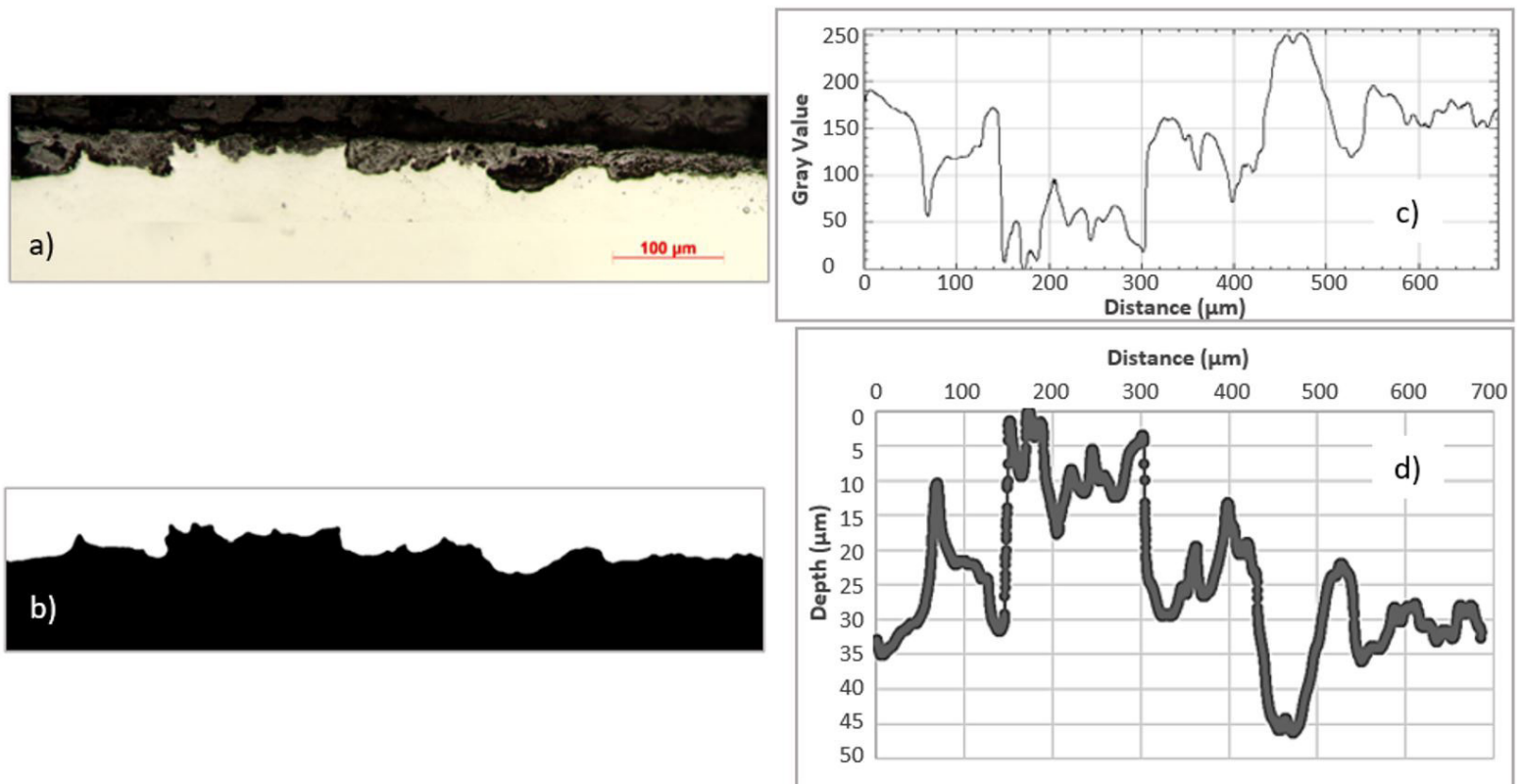

Figure 2. Binarization process and surface profile plotting. Surface micrography (a); binarized image (b); surface profile plot (c); depth $\times$ distance plot $(\mathrm{d})$.
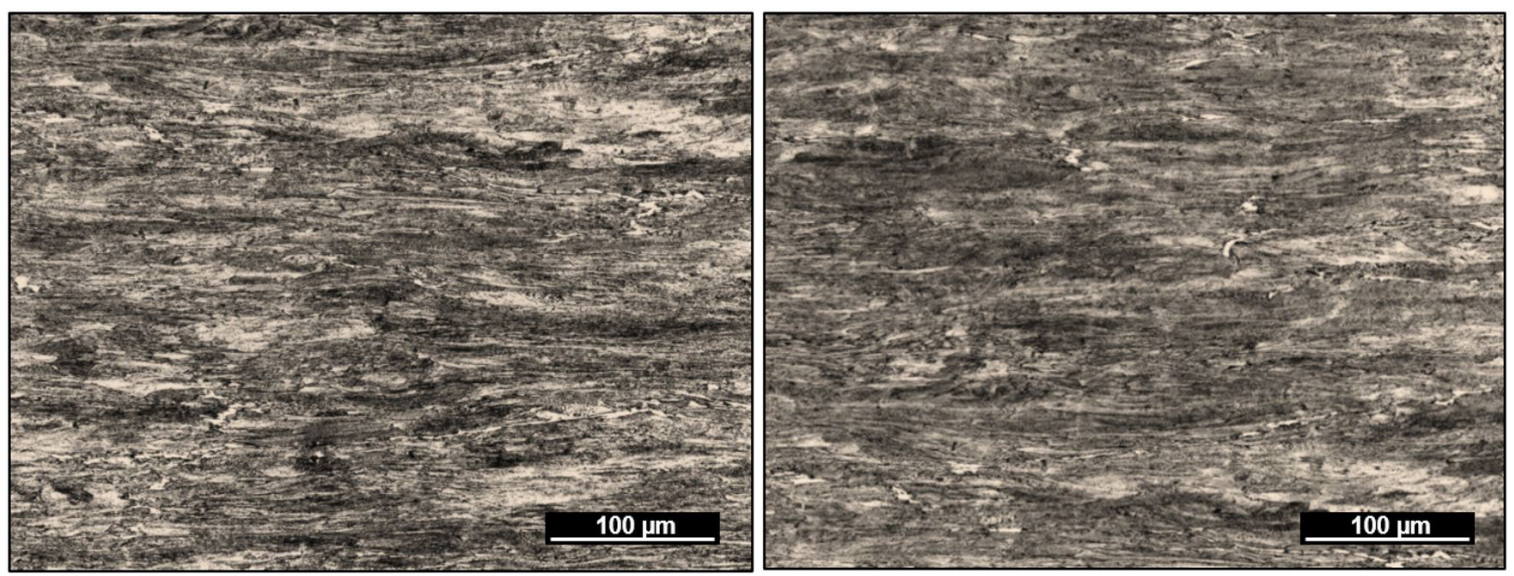

Figure 3. Wire micrography. Wire 1 at left, wire 2 at right. Elongated pro-eutectoid ferrite (light phase) and perlite (dark phase). 

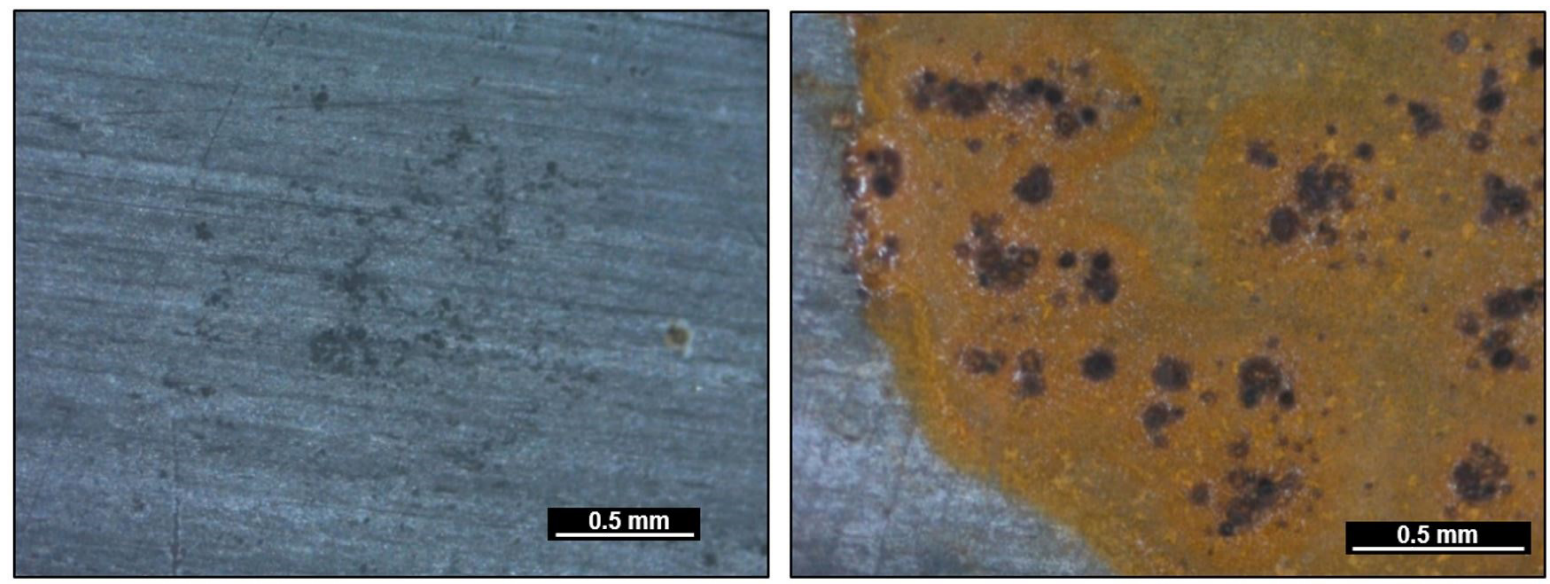

Figure 4. W1 and PW1 representative micrograph comparison. Left: W1 specimen; Right: PW1 specimen.
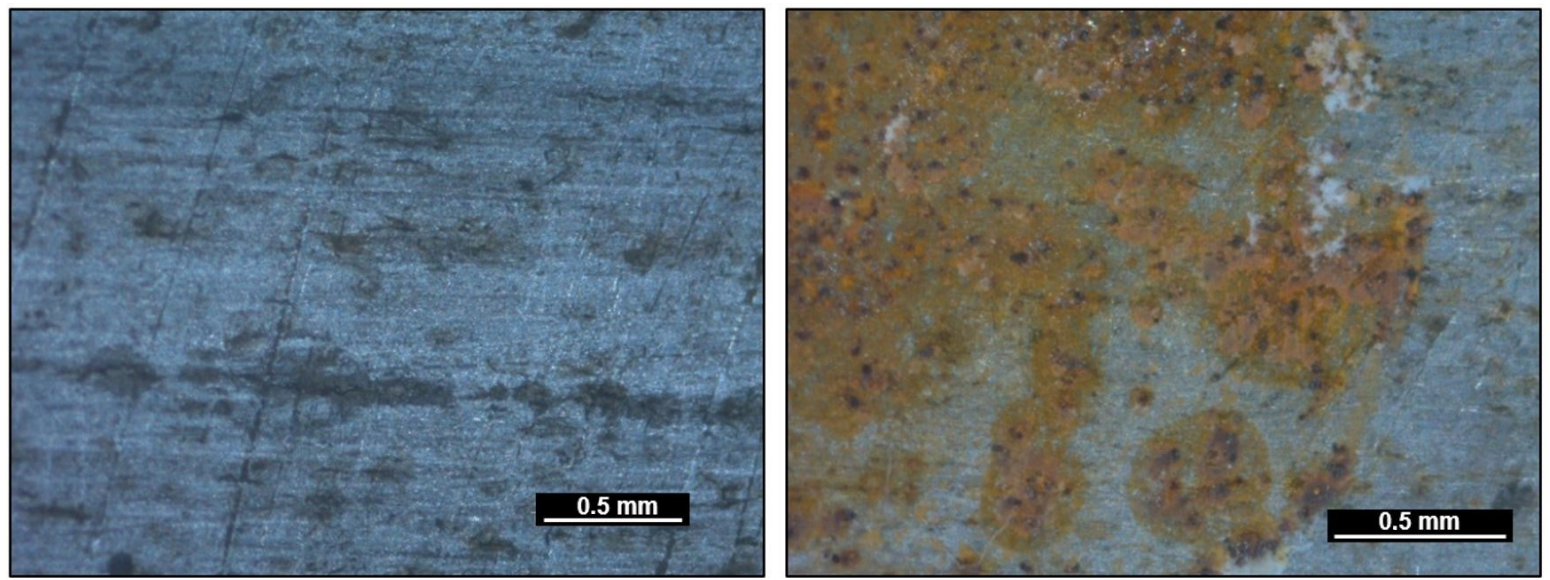

Figure 5. W2 and PW2 representative micrograph comparison. Left: W2 specimen; Right: PW2 specimen.
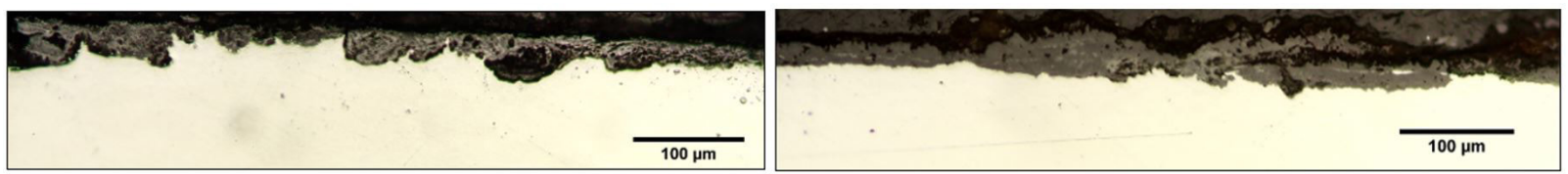

Figure 6. Representative SC tested wires' cross section micrographs. Left column: PW1; Right column: W1.

iron oxide films were formed early and due to occlusive effect of crevices [20,21].

Yang et al. [22] compared current density and fluctuations of inverse potential corrosion when the pitting corrosion phase of A516 steel $(0.35 \% \mathrm{C})$ in the chloride ion solution is reached. During the time of immersion, fluctuations became more frequent. At the same time, filiform pitting, typical of crevice corrosion, were observed by the authors. The instability of the current density signals, accompanied by increasingly frequent and intense current spikes, indicates different corrosion rates from the rest of the system proposed by the authors. The values, therefore, were severely higher than those observed for general corrosion in their study. This parameter is essential for understanding the effect of crevice corrosion on carbon steel and has been widely expanded to more aggressive environments, such as saline solutions under high pressures and saturated with
$\mathrm{CO} 2$, as summarized by Barker et al. [23] and evaluated by our present study.

Some representative sections of pitting analysis are shown in Figure 6. Pitting's of the PW group were more frequent and notable for their elliptical shape. Pitting's of group $\mathrm{W}$ were less frequent and had shallow geometry, which denotes less aggressive corrosion. Therefore, crevice geometry directly influences localized corrosion. No significant differences were found between wires 1 and 2, as well as between PW1 and PW2.

Hua et al. [14] evaluated the general and pitting corrosion rates on semi-polished UNS G15130 (0.12\% C) carbon steel. Their tests were carried out at $8 \mathrm{MPa}$ partial $\mathrm{CO}_{2}$ pressure, $35^{\circ} \mathrm{C}$ and presented $0.1 \mathrm{~mm} /$ year general corrosion rate and, with saturation of $\mathrm{CO}_{2}$, promoted pitting corrosion rate of about $1 \mathrm{~mm} /$ year. Their samples tested after $48 \mathrm{~h}$ showed narrow cavities of about $10 \mu \mathrm{m}$ depth. Similar 
values were observed by Farelas et al. [24], contemplating $\mathrm{CO}_{2}$-saturation direct effect on localized corrosion severity. Their results contribute to the understanding of the considerable effect of $\mathrm{CO}_{2}$ saturation on the increase of localized corrosion observed in our study.

Li et al. [20] evaluated API N80 $(0.42 \%$ C) carbon steel crevice and bending stress synergistic effects under $\mathrm{CO}_{2}$-saturated aqueous solution and they noted that corrosion rate increases with stress. Their study noticed that marked deepening in the cavities in the occluded regions was detected when the combined effect of stress and crevice was analyzed. They also verified that the depth increases twice when compared to the non-occluded surface, results that statistically endorse the deleterious effect of $\mathrm{CO}_{2}$-saturation on riser tensile carbon steel armor wires. It is important to note that in our test, $\mathrm{CO}_{2}$ has not been renewed, so that part of the gas may have been transformed by reactions with metal. Even so, we achieved significant differences between groups, as explained.

Results of pitting frequency and depth for each group are illustrated in Figure 7:

- PW1: a 36 pitting frequency and $33.2( \pm 13.4) \mu \mathrm{m}$ average depth;

- W1: 25 pitting frequency and $24.4( \pm 13.9) \mu \mathrm{m}$ average depth;

- PW2: 27 pitting frequency and $41.3( \pm 17.5) \mu \mathrm{m}$ average depth;

- W2: 19 pitting frequency and $29.6( \pm 9.7) \mu$ m average depth;

- ANOVA showed $0.00007 \mathrm{p}$-value between groups and $\mathrm{F}$-value $=8.06$, higher than critical F-value $=2.69$.

According to $\mathrm{Hu}$ et al. [25], $\mathrm{CO}_{2}$-saturated brine carbon steel crevice corrosion is related to inside crevice cathodic species consumption, such as $\mathrm{H}^{+}$and $\mathrm{H}_{2} \mathrm{CO}_{3}$, promoting undesirable galvanic corrosion effect. Crevice occluded surface is preferably corroded resulting severe localized corrosion. Under-crevice surface acts as anode and free surface acts as cathode, explaining PW specimens' rougher surfaces. Their study corresponds to the results of our work about the differential aeration phenomenon and its influence on localized corrosion of occluded surfaces.

Cathodic species consumption causes system's and crevice subsystem's $\mathrm{pH}$ increase, as presented by Panossian and Cardoso [26] and $\mathrm{Li}$ et al. [21]. Furthermore, $\mathrm{Cl}^{-}$ions concentration and crevice differential aeration increase. Combined with the increase in $\mathrm{pH}$, these effects lead to negative corrosion potential displacement when compared to free surface.

The above described mechanism, acting alone, would result in occluded surface's severe corrosion and virtually uncorroded free surface. However, pitting's acidification and passive films weakening are associated with this mechanism [27]. Pitting's acidification, related to Fe-ions hydrolysis, causes $\mathrm{Fe}^{2+}$ concentration increase and $\mathrm{H}+$ consumption compensation. In evaluated test system $\left(\mathrm{CO}_{2}\right.$-saturated crevice regions) prevails galvanic corrosion mechanism, characteristic of deaerated systems [28]. Our system here has a high steel to electrolyte ratio, so which it will work almost as a buffered solution (over saturation). So, the impact might not be so relevant.

Raman spectroscopy denoted siderite and cementite, typical compounds that are formed from ferritic-pearlitic carbon steel operating in deep $\mathrm{CO}_{2}$-saturated waters $[29,30]$. Raman analysis (Figure 8) showed siderite and cementite in the two wire configurations tested, although peak defaults occurred in relation to the literature [31,32].

For the siderite case, there is coincidence in carbonate ions $\left(\mathrm{CO}_{3}{ }^{2-}\right)$ symmetrical stretching mode intensity at $1088 \mathrm{~cm}^{-1}$ [31]. Regarding to cementite, our sample peaks coincide with D (amorphous) and G (crystalline) graphite bands [32]. According to Gronebaum and Pluschkell [33], graphite $\mathrm{D}$ band occurs for Raman displacement closer to $1300 \mathrm{~cm}^{-1}$ and corresponds to amorphous sp $\mathrm{sp}^{2}$-linked carbon

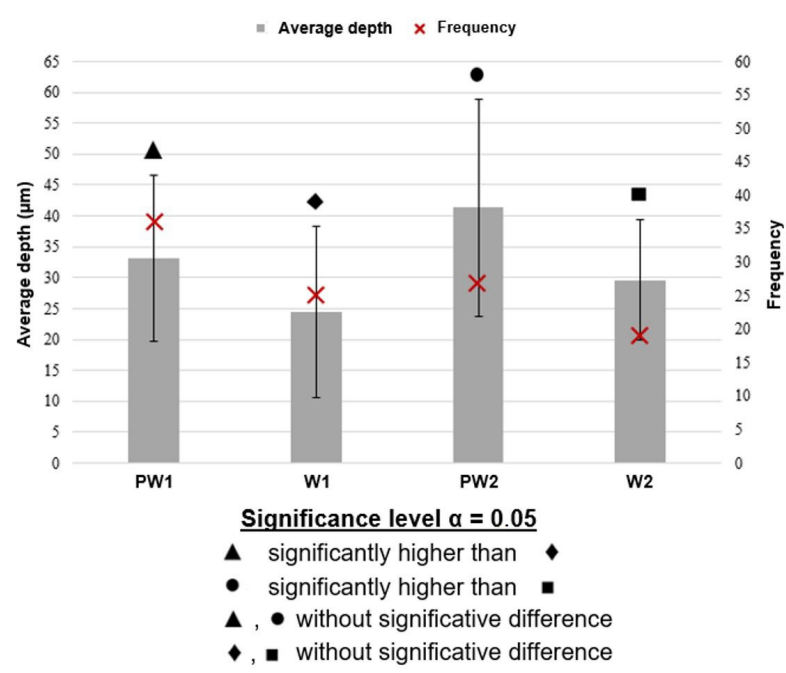

Figure 7. Pitting average depth and frequency for each SC test wire TPB assembly.

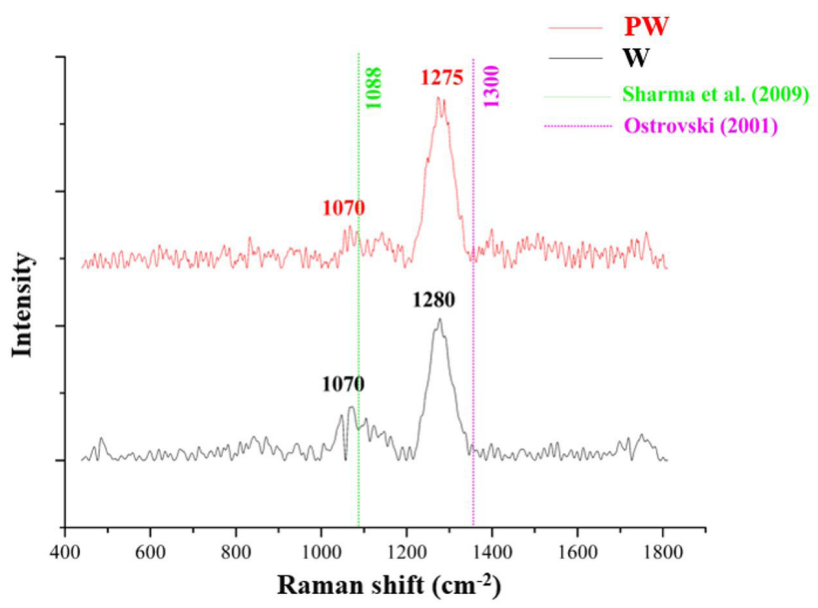

Figure 8. Raman spectra of pitting deposits of PW and W. 
species, being predominant phase in cementite and, therefore, most relevant peak for comparison.

Dugstad et al. [34] evaluated the outer polymeric layer eventual failure emulation and consequent ingress of seawater in the annulus, in direct contact with carbon steel wire. In their study, passive layer properties of siderite were studied when exposed to aerated ocean water. Their results exposed a siderite film formation reduced material corrosion rate by about one hundred times, due to its system solution supersaturation.

Similarly, our study founded film superficial damage after environment aeration, resulting in the formation of cementite porous and active film, increasing corrosion

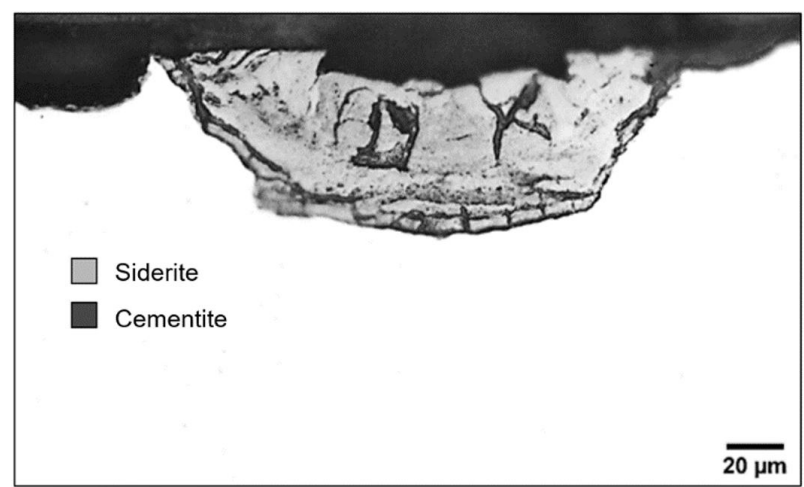

Figure 9. Shallow and wide pitting with siderite deposit.
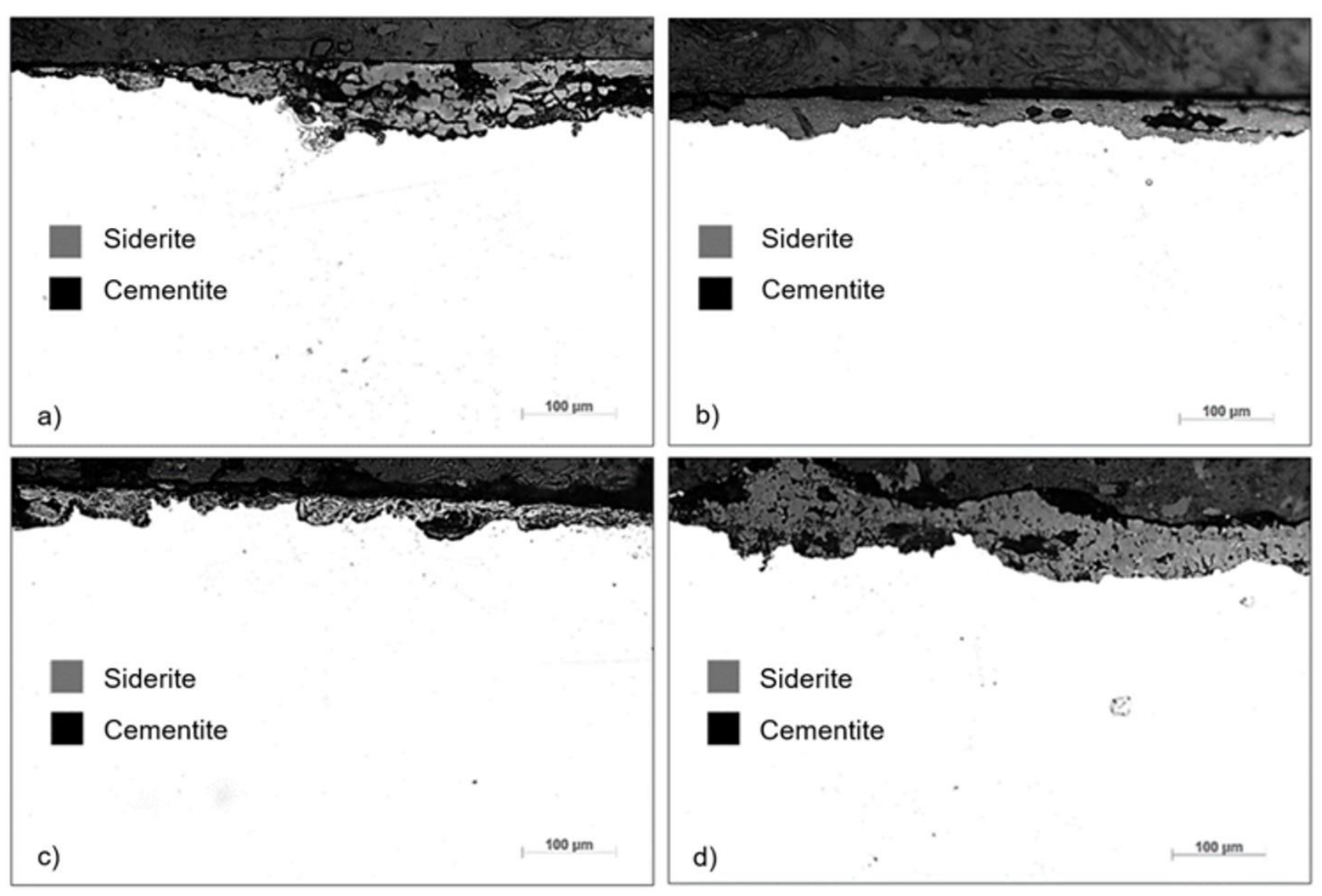

Figure 10. Wires cross-section and characterization of siderite and cementite deposits. (a) PW1; (b) W1; (c) PW2; (d) W2. rate to higher rates than showed by previous siderite films. Therefore, differential aeration and crevice corrosion potential effects can be related to our results, since siderite occurred on the thin surface layers of cementite of about $5 \mu \mathrm{m}$, as verified by Berntsen et al. [35] in his study of relationship between siderite saturation and cementite films.

Such configuration was noticed in PW-assemblies, while in $\mathrm{W}$-assemblies iron carbide deposits adhered directly to metallic substrate, suggesting, therefore, intermittence of pitting deepening. Figure 9 shows a shallow and wide pitting with siderite deposit associated with cementite film, while Figure 10 shows each tested group deposit arrangements. According to Kermani and Morshed [29] and Crolet [27], it is possible to justify a greater propensity to deepen the pitting, which can be detected by plotting a cross-sectional surface when analyzing the overlap order of siderite and cementite deposits on the samples surface.

For PW-assemblies (Figures 10), it is possible to observe cementite film (in black) consolidation and partial siderite layers (in light gray) deposition associated with more cementite depositions, a non-protective layer disposition. On the other hand, when observing $\mathrm{W}$-assembly microscopies, it was possible to observe a consolidated siderite layer associated with partial cementite depositions, a protective layer's singular arrangement. 


\section{Conclusions}

The objective of the present study was to analyze tensile armor localized corrosion under deep-water atmosphere of $\mathrm{CO}_{2}$-saturated corrosive environment, to understand the stress corrosion occurrence associated with crevice corrosion. Immersion tests were carried out at $20 \mathrm{bar}$ and $60^{\circ} \mathrm{C}$.

The following conclusions could be achieved:

- No significant difference between carbon steel wires 1 and 2 behavior was found. Crevice effect, simulated by HDPE layer addition, is dominant in relation to the carbon content;

- Corrosion tests presented the significant effect of crevice to the formation of deeper pitting in more quantity. Wire 1 had a $44 \%$ higher pitch frequency and wire 2 had a $42 \%$ higher pitch frequency when accompanied by the HDPE layer. The occurrence of crevice significantly affects the localized corrosion of the wires. This problem is very likely with flexible risers;

- The severity of pitting corrosion in the PW group seems to be related to the deposits arrangements, despite the composition of the deposits being the same (cementite and siderite). The PW group showed greater adhesion of cementite to the steel surface, i.e., brittle passive cementite layer.

\section{Acknowledgements}

Authors would like to thank the financial agencies $\mathrm{CNPq}$ and CAPES.

\section{References}

1 Sertã OB, Longo CEV, Roveri FE. Riser systems for deep and ultra-deepwaters. In: Proceedings of the Offshore Technology Conference; 2001; Texas. Texas: Tex. Technology Transfer; 2001.

2 Håbrekke S, Hokstad P. Ageing and life extension for safety systems on offshore facilities. In: Berenguer C, Grall A, Soares CG. Advances in safety, reliability and risk management. London: CRC Press; 2011. p. 1547-1554.

3 Goldemberg J, Schaeffer R, Szklo A, Lucchesi R. Oil and natural gas prospects in South America: can the petroleum industry pave the way for renewables in Brazil? Energy Policy. 2014;64:58-70.

4 Awadh SM, Al-Mimar H. Statistical analysis of the relations between API, specific gravity and sulfur content in the universal crude oil. International Journal of Scientific Research. 2015;4:1279-1284.

5 Kermani MB, Harrop D. The impact of corrosion on oil and gas industry. SPE Production \& Facilities. 1996;11(3):186-190.

6 Kermani B, Harrop D. Corrosion and materials in hydrocarbon production. Newark: John Wiley \& Sons; 2019.

7 Bai Y, Bai Q, Ruan W. Advances in pipes and pipelines: flexible pipes. 1st ed. Hoboken: Wiley; 2017. p. 278-315.

8 Bai Y, Bai Q. Subsea engineering handbook. Cambridge: Elsevier; 2010. Overview of subsea engineering; p. 3-25.

9 Drumond GP, Pasqualino IP, Pinheiro BC, Estefen SF. Pipelines, risers and umbilicals failures: a literature review. Ocean Engineering. 2018;148:412-425.

10 Leira B, Berge S, Løtveit S-A, Fergestad D, Langhelle N. Lifetime extension of flexible risers: a generic case study. Offshore Technology Conference; 2015; Texas. Texas: Tex. Technology Transfer; 2015.

11 Nagano H. Pitting and crevice corrosion. Journal of the Society of Materials Science. 1978;27:309-314.

12 Beavers J, Bubenik TA. Stress corrosion cracking. In: Sherik A, El-Sherik AM. Trends in oil and gas corrosion research and technologies. Oxford: Elsevier; 2017. p. 295-314.

13 Hatton S. Effects of high temperature on the design of deepwater risers. Houston, TX: 2H Offshore; 2003.

14 Hua Y, Barker R, Neville A. Understanding the influence of $\mathrm{SO}_{2}$ and $\mathrm{O}_{2}$ on the corrosion of carbon steel in watersaturated supercritical $\mathrm{CO}_{2}$. Corrosion. 2015;71(5):667-683.

15 Liu Z, Gao X, Du L, Li J, Kuang Y, Wu B. Corrosion behavior of low-alloy steel with martensite/ferrite microstructure at vapor-saturated $\mathrm{CO}_{2}$ and $\mathrm{CO}_{2}$-saturated brine conditions. Applied Surface Science. 2015;351:610623.

16 ArcelorMittal. Guia do aço. São Paulo; 2013.

17 American Society for Metals. Metallography and microstructures of carbon and low-alloy steels. In: Vander Voort GF. Metallography and microstructures. Materials Park: ASM International; 2004. p. 608-626.

18 Tagliari MR, Antunes MR, Santos JGN, Santos FP, Santos JMC, Falcade T, et al. Tensile armor wires submitted to slow strain rate tests in a corrosive environment and cathodic protection: a comparison between two different microstructures. Materials Research. 2019;22(3):e20180465. 
19 American Society for Metals. Materials properties handbook: titanium alloys. 1st ed. Materials Park: ASM International; 1994.

$20 \mathrm{Li}$ YZ, Guo XP, Zhang GA. Synergistic effect of stress and crevice on the corrosion of N80 carbon steel in the $\mathrm{CO}_{2}$ -saturated $\mathrm{NaCl}$ solution containing acetic acid. Corrosion Science. 2017;123:228-242.

$21 \mathrm{Li}$ YZ, Xu N, Liu GR, Guo XP, Zhang GA. Crevice corrosion of N80 carbon steel in $\mathrm{CO}_{2}$-saturated environment containing acetic acid. Corrosion Science. 2016;112:426-437.

22 Yang MZ, Wilmott M, Luo JL. Crevice corrosion behavior of A516-70 carbon steel in solutions containing inhibitors and chloride ions. Thin Solid Films. 1998;326(1-2):180-188.

23 Barker R, Hua Y, Neville A. Internal corrosion of carbon steel pipelines for dense-phase $\mathrm{CO}_{2}$ transport in carbon capture and storage (CCS): a review. International Materials Reviews. 2016;62(1):1-31.

24 Farelas F, Choi YS, Nešić S. Corrosion behavior of API 5L X65 carbon steel under supercritical and liquid carbon dioxide phases in the presence of water and sulfur dioxide. Corrosion. 2013;69(3):243-250.

$25 \mathrm{Hu}$ Q, Guo X, Zhang G, Dong Z. The corrosion behavior of carbon steel in CO2-saturated NaCl crevice solution containing acetic acid. Mater Corros. 2012;63(8):720-728.

26 Panossian Z, Cardoso JL. Interpretação de curvas de polarização. In: INTERCORR; 2014; Fortaleza. Fortaleza: ABRACO; 2014.

27 Crolet J-L. Protectiveness of corrosion layers. In: Modelling Aqueous Corrosion; 1993; Plymouth, U.K. Netherlands: Springer; 1994. p. 1-28.

28 Galvele JR. Transport processes and the mechanism of pitting of metals. Journal of the Electrochemical Society. 1976;123(4):464.

29 Kermani MB, Morshed A. Carbon dioxide corrosion in oil and gas production: a compendium. Corrosion. 2003;59(8):659-683.

30 Jasinski R. Corrosion of N80-type steel by $\mathrm{CO}_{2}$ /water mixtures. Corrosion. 1987;43(4):214-218.

31 Sharma SK, Misra AK, Lucey PG, Lentz RCF. A combined remote Raman and LIBS instrument for characterizing minerals with 532nm laser excitation. Spectrochimica Acta. Part A: Molecular and Biomolecular Spectroscopy. 2009;73(3):468-476.

32 Park E, Ostrovski O, Zhang J, Thomson S, Howe R. Characterization of phases formed in the iron carbide process by X-ray diffraction, mossbauer, X-ray photoelectron spectroscopy, and raman spectroscopy analyses. Metallurgical and Materials Transactions. B, Process Metallurgy and Materials Processing Science. 2001;32(5):839-845.

33 Gronebaum RH, Pluschkell W. Investigations on the Iron Carbide Formation Reaction. In: Proceedings of the Conference on "Pre-reduced products and Europe"; 1996; Milan. Milan: AIM; 1996. p. 204-213.

34 Dugstad A, Palencsár S, Berntsen T, Børvik L. Corrosion of steel armour wires in flexible pipes: history effects. In: SPE International Oilfield Corrosion Conference and Exhibition; 2018; Richardson, TX. Texas: Society of Petroleum Engineers; 2018.

35 Berntsen T, Seiersten M, Hemmingsen T. Effect of $\mathrm{FeCO}_{3}$ supersaturation and carbide exposure on the $\mathrm{CO}_{2}$ corrosion rate of carbon steel. Corrosion. 2013;69(6):601-613.

Received: 14 Aug. 2020

Accepted: 18 Jan. 2021 